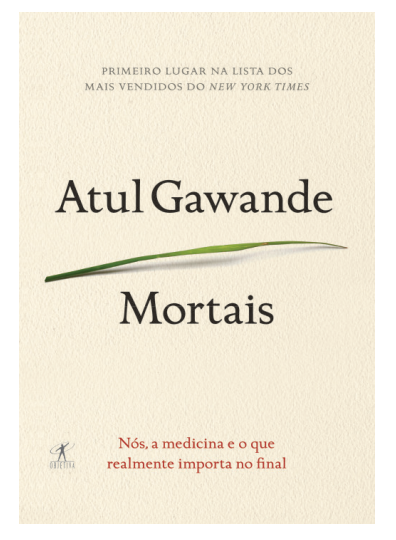

\section{Mortais - autonomia e solidariedade em resposta à insuficiência da medicina}

Como as sociedades lidam com seus indivíduos idosos? O que fazer com aqueles que têm doenças progressivas e incuráveis? As perguntas centrais do livro do cirurgião norte-americano Atul Gawande conduzem à exploração de uma temática relevante para as sociedades contemporâneas, confrontadas com o desafio do fenômeno global do envelhecimento. Gawande atua como professor do Departamento de Saúde Pública e Administração da Harvard School of Public Health e do Departamento de Cirurgia da Harvard Medical School. Mortais ${ }^{1}$, seu quarto livro, lançado em 2014 e publicado no Brasil no ano seguinte, dialoga com referenciais teóricos da sociologia e da antropologia.

Gawande parte da observação de que a Faculdade de Medicina não ensina o médico a lidar com o fim da vida de seus pacientes. Howard Becker $^{2}$, em Boys in White, e Byron $\mathrm{Good}^{3}$, em How Medicine Constructs its Objects, já apontaram como o ensino médico forma profissionais para a vida acadêmica, com ênfase na doença, em detrimento de um vínculo genuíno com a pessoa doente.
Gawande A. Mortais. Rio de Janeiro: Objetiva; 2015.

Daniel Lima Azevedo(a)

Gawande confessa seu desamparo diante de situações de terminalidade: "encontrei pacientes que eram forçados a enfrentar a realidade do declínio e da mortalidade, e não levei muito tempo para perceber o quão despreparado eu estava para ajudá-los" (p. 13). O fascínio pela biotecnologia disponível nas unidades de terapia intensiva, ele alerta, pode gerar formas elaboradas de tortura, pois os pacientes são submetidos a infindáveis procedimentos de manutenção de vida e não conseguem morrer.

Que tipo de medicina é essa? Assim como o historiador francês Philippe Ariès ${ }^{4}$, que investigou as atitudes das sociedades diante da morte, na Europa, da Idade Medieval ao fim do século XX, Gawande pondera que a morte permanece oculta nos hospitais, no início do novo milênio: "[...] as pessoas estão cada vez menos familiarizadas com os estágios finais da vida" ( $p$. 16). Até o século XIX, a morte era um acontecimento social, significativo para o moribundo e para sua família. A partir de então, especialmente a partir da segunda metade do século $X X$, torna-se uma experiência médica, na qual somente o médico detém o poder de autorizar o indivíduo a morrer. Essa perversão do propósito da medicina condena as pessoas, em tal momento (a) Instituto de Estudos em Saúde Coletiva, Universidade Federal do Rio de Janeiro. Avenida Horacio Macedo, s/n, Ilha do Fundão, Cidade Universitária.

Rio de Janeiro, RJ, Brasil. 21941-598. daniel.lima.azevedo@ gmail.com 
histórico, a morrerem sós, em instituições nas quais "rotinas regradas, anônimas, nos isolam de tudo o que nos é importante na vida" (p. 19).

O envelhecimento da população mundial é inquestionável e transcorre com velocidades diferentes nos dois hemisférios. Na Europa e América do Norte, aconteceu depois que os países alcançaram certa maturidade, com redução de desigualdades sociais e econômicas. $\mathrm{Na}$ América Latina, o processo dá-se antes da ocorrência dessa estabilidade, em meio a um cenário de economias frágeis, níveis crescentes de pobreza e dificuldades no acesso ao sistema de saúde ${ }^{5}$. Nesse horizonte de disparidade, as formas de lidar com os idosos diferem de acordo com cada sociedade e sua respectiva estrutura familiar. O antropólogo Lawrence Cohen ${ }^{6}$ refere que, na Índia, os idosos são considerados como responsabilidade da família, que os acolhe inclusive quando eles apresentam alta dependência para as atividades do dia a dia. É a expectativa natural. O próprio Gawande, descendente de indianos, recorda que seu avô se tornou centenário e recebeu cuidados em casa até o momento da morte. Ele aponta uma inversão de valores nas sociedades ocidentais contemporâneas, nas quais idosos e doentes vivem sozinhos e isolados "[...] em uma série de instalações anônimas, na qual passam seus últimos momentos de consciência com enfermeiras e médicos que mal sabem seus nomes" (p. 23). As atitudes sociais concernentes à velhice mudaram, nos Estados Unidos, ao longo do século $X X$ : de exemplos de dignidade $e$ sabedoria, os idosos passaram a ser considerados como refugos decrépitos. $\mathrm{O}$ aumento da expectativa do tempo de vida e a redução das taxas de fecundidade, que ocorreram nesse período, geraram novos arranjos intergeracionais. A sociedade contemporânea tornou-se hedonista. Desconhece a transcendência, enfatiza a fisicalidade e, portanto, não percebe uma finalidade para seus velhos dependentes, sem se dar conta de que, com o envelhecimento, a perda da independência é inelutável: tornarse dependente ao fim da vida é uma situação previsível na trajetória de quase todos.

Na primeira metade do século $X X$, morriase de forma brusca por causa vascular ou infecção aguda. O acesso à tecnologia alterou as trajetórias das doenças. No início do século $X X I$, no entanto, essas doenças são passíveis de intervenções capazes de estender a vida dos indivíduos, porém, com a possibilidade de longos períodos em que eles apresentam sequelas. Ao abordar a fisiologia do envelhecimento, Gawande dialoga com o filósofo francês Georges Canguilhem ${ }^{7}$ e descreve como o corpo sofre transformações às quais a pessoa adapta-se. Há um momento, porém, em que se instala uma vulnerabilidade orgânica, e a pessoa começa a "cair aos pedaços": é a síndrome de fragilidade, um diagnóstico que marca uma trajetória de fim de vida cada vez mais frequente. Gawande observa que os médicos sentem-se impotentes diante de uma senhora frágil, com múltiplos problemas de saúde, e podem indicar tratamentos que inadvertidamente piorem sua qualidade de vida. O autor enaltece a intervenção de geriatras, dedicados a rever os medicamentos prescritos, as prioridades dos pacientes e suas redes de suporte. Lamenta que o número de médicos dessa especialidade seja insuficiente, nos Estados Unidos, para atender a população idosa.

No livro Patrimônio ${ }^{8}$, o romancista norteamericano Philip Roth detalha as perdas decorrentes da doença de seu pai, que se torna progressivamente dependente, até o impactante episódio de incontinência que dá título ao livro. Lidar com a perda da independência de um ente querido é devastador. Com base no filósofo francês Michel Foucault ${ }^{9}$, Gawande descreve os asilos do início do século XX como locais sombrios. A violência sofrida pelos residentes nessas instituições encontra-se registrada em fontes históricas e em romances, a exemplo de As we are now ${ }^{10}$, com um fim apocalíptico: uma idosa que mora em um asilo, inconformada com a falta de tratamento digno, ateia fogo à edificação e morre no incêndio que provocou.

Em países periféricos, os asilos tornamse cada vez mais numerosos, pois as famílias reduzidas e empobrecidas não conseguem absorver os cuidados com os idosos. Gawande resgata as origens históricas das casas de repouso modernas, que remontam à década de 1950. Os hospitais assumiam um poder crescente, exercido pelo controle das rotinas dos pacientes, mediante a possibilidade de oferta de intervenções curativas $^{11}$. Entretanto, não conseguiam resolver problemas decorrentes de doenças crônicas e da velhice. Começaram a ficar repletos de pacientes. A partir de então, o governo norte-americano passou a remunerar instituições dispostas a 
receber pacientes egressos de hospitais. Nessa perspectiva histórica, as casas de repouso não surgiram com o propósito de maximizar o potencial ou a qualidade de vida dos pacientes, mas "foram criadas para liberar leitos nos hospitais" (p. 73). A privacidade e a autonomia, definida como capacidade de autodeterminação, são pulverizadas por esse modelo, com consequências para o paciente ${ }^{12}$.

Gawande pondera que as casas de repouso deveriam se dedicar a cuidar dos idosos, mas, na prática, assemelham-se às "instituições totais" de Erving Goffman ${ }^{13}$, com rotinas rigorosas, atividades obrigatórias e vigilância constante. Essa ideia é reforçada por outro livro recente, que relata os embates dos idosos de uma instituição de longa permanência holandesa com a administração $0^{14}$. Gawande reconhece que as casas de repouso contemporâneas não se comparam aos asilos do início do século XX, mas reforça a ideia de que, para a sociedade, as pessoas parecem perder a importância quando se tornam dependentes. Ainda de acordo com o autor, os maus-tratos sofridos nas instituições são "[...] consequência de uma sociedade que lida com a fase final do ciclo de vida humano tentando não pensar a respeito dela" (p. 78). Instituições contemporâneas oferecem modelos inovadores de cuidado, com ênfase no respeito à autonomia e privacidade, e assemelhamse à proposta de um lar - integram conforto e companhia pela flexibilização de regras. Lamentavelmente, essas moradias assistidas adaptam-se cada vez mais às expectativas dos filhos dos idosos, que costumam ser os contratantes do serviço: "tudo o que resta a nossos idosos é uma existência institucional, controlada e supervisionada, uma resposta desenvolvida clinicamente para problemas incorrigíveis, uma vida projetada para ser segura, porém vazia de tudo aquilo que lhes é importante" (p. 107). O binômio autonomia $X$ segurança encontra-se no cerne do livro e fomenta a discussão de que, embora as pessoas desejem exercer seu livre arbítrio em relação a suas vidas, preferem que seus entes queridos idosos estejam em segurança, ainda que isso signifique ignorar suas vontades. Promover a autonomia corresponde a estimular que o indivíduo mantenha-se como protagonista de sua própria vida, conduzindo-a de acordo com seus princípios e prioridades até o momento da morte.
Diante de uma doença incurável em fase avançada, como um câncer metastático, qual deve ser a atitude do médico? As preocupações de pessoas nessa situação envolvem uma ressignificação dos relacionamentos, a vontade de não sofrer e a possibilidade de resolução de pendências. A resposta do sistema de saúde, no entanto, frustra essas expectativas ao prover cuidados baseados em tecnologia que ignoram a importância da sensação de completude. $\mathrm{Na}$ idade medieval, guias sobre a ars moriendi, a arte de morrer, ensinavam a adoção de uma atitude estoica diante da morte, percebida como transição para a vida eterna cristã. Durante o processo de morrer, era fundamental pedir perdão pelos pecados, reafirmar a crença em Deus e delegar as posses aos familiares. Havia um propósito discernível para o sofrimento e uma cartilha a seguir: alcançar o Paraíso mediante um comportamento de resignação. Contudo, a sociedade contemporânea secularizou-se e o hedonismo é valor hegemônico, dirigido ao momento imediato, condições que contribuem para uma aversão à morte e a transferência do poder dos representantes religiosos para os médicos ${ }^{15}$. Nessa transição histórica, consagra-se o emprego de expressões de caráter bélico para a descrição de tratamentos, a exemplo de "luta contra o câncer" e "arsenal terapêutico", como indica a filósofa e pensadora Susan Sontag ${ }^{16}$. Lidar com a morte converteu-se em uma batalha. A ideia central de Gawande é que "nas últimas décadas, a ciência médica tornou obsoletos séculos de experiência, tradição e linguagem relativas à nossa mortalidade e criou uma nova dificuldade para a humanidade: como morrer" ( $p$. 151).

A preparação da pessoa para a morte, conforme Gawande, pode ser facilitada pela introdução de cuidados paliativos, definidos pela Organização Mundial da Saúde ${ }^{17}$ :

[...] como uma abordagem que promove qualidade de vida de pacientes (de todas as idades) e seus familiares diante de doenças que ameaçam a continuidade da vida. Previnem e aliviam o sofrimento por meio da identificação precoce e do tratamento correto da dor e de outros problemas de natureza física, psicossocial e espiritual. Promovem dignidade, qualidade de vida e acomodação à progressão da doença, 
usando as melhores evidências científicas disponíveis. (tradução de minha autoria).

Na concepção de Gawande, os cuidados paliativos representam a possibilidade de resgate de uma ars moriendi para a era atual, pois permitem que o paciente retome seu lugar de direito como protagonista de sua biografia, o que demanda conversas significativas com a equipe sobre suas preferências para o fim da vida. Estabelecer esse diálogo compete aos médicos que, para o autor, furtam-se de lidar com a questão da mortalidade e, consequentemente, decidem por tratamentos de manutenção da vida que são danosos aos enfermos e angustiam os familiares. Discutir o fim da vida com os doentes é tarefa delicada, que requer sensibilidade e treinamento. Acrescente-se que depende do estabelecimento de um vínculo e de tempo para reflexão. Para os pacientes, "aceitar [a] própria mortalidade e chegar a uma clara compreensão dos limites e das possibilidades da medicina é um processo, não uma epifania" (p. 173). A função da medicina seria negociar esse entendimento e propor tratamentos proporcionais às doenças, garantindo o bem-estar. Os médicos enganamse ao acreditar que seu trabalho seja garantir a saúde e a sobrevivência e tendem a adotar duas posturas: a paternalista, em que exercem seu poder de decisão, por considerar tratar-se do melhor para o enfermo, ou a informativa, em que repetem fatos e números e solicitam que o paciente escolha o tratamento a partir dessas informações. Gawande critica tais posturas e reflete que "a atitude não apenas correta, mas também necessária, a ser tomada pelo médico é a de discutir com os pacientes a respeito de suas metas mais amplas e até de desafiá-los a repensar prioridades e crenças irrefletidas" (p. 191).

O livro culmina no relato da doença do pai do autor, um médico urologista diagnosticado com um tipo raro de tumor da medula espinhal que provoca fortes dores cervicais e compromete a força de seus membros. As intervenções para controle da doença envolveram cirurgia, quimioterapia e radioterapia. Não foram bemsucedidas e deixaram a família com um misto de desorientação e desespero. Gawande hesita em conversar com o pai sobre sua admissão em um serviço de cuidados paliativos: "a mera menção traria o assunto sombrio e intocável da morte para a mesinha de centro entre nós" (p. 211). No entanto, a visita de uma enfermeira especialista em cuidados paliativos permite uma melhora no controle da dor e a expressão de sentimentos pelo pai, que incluem raiva pela situação de impotência e o desejo de não ser hospitalizado. Ao fim, o pai permanece em casa, com o corpo nu e frágil manipulado pela família, deliciandose com fotos dos netos nos intervalos dos períodos de confusão mental e com a respiração controlada por medicamentos, até morrer.

Gawande refere-se aos tipos de coragem necessários na velhice e na doença. O primeiro diz respeito ao enfrentamento da realidade de ser mortal. O segundo tipo de coragem requer que os atos de uma pessoa reflitam a verdade que ela descobre sobre seus medos e esperanças. Ao retomar a discussão da autonomia, cabe lembrar um estudo primoroso sobre as solicitações de eutanásia na Holanda ${ }^{18}$. Uma importante conclusão dessa pesquisa é que a maior parte dos pedidos não se converte em eutanásias de fato. Antes, representam uma estratégia que resta ao paciente, para que ele sinta estar no controle do fim da própria vida - um sentimento de controle que é parte indissociável da cultura holandesa e que corresponde ao expoente máximo da autodeterminação. Gawande discute o suicídio assistido e posiciona-se como seu opositor. Para ele, a possibilidade de acelerar a morte poderia afastar sociedades inteiras do objetivo de melhorar a vida dos doentes, repleta de possibilidades. Ele defende a importância de acolher as demandas de quem está próximo ao fim da vida, com o firme propósito de terminar sua história da melhor forma possível. O processo de despedida é importante, tanto para a pessoa que está morrendo quanto para sua família. O uso desmedido de tecnologia nessa fase da doença consiste em uma calamidade: " $[$...] a maneira como negamos [o processo de morrer] às pessoas, por obtusidade e por negligência, é motivo de vergonha eterna" (p. 233).

Ser humano é ser limitado; é ser dotado de um corpo cujos órgãos inevitavelmente apresentarão sinais de fragilidade e falência, que acarretarão incapacidade funcional e dependência. Cada pessoa traça metas para sua vida, e a medicina precisa adequar suas intervenções para que se possa alcançar essas metas. "A única maneira de dar sentido à morte é nos enxergando como parte de algo maior: uma família, uma comunidade, uma sociedade. Se não o fazemos, a mortalidade 
é simplesmente algo terrível. Porém se o fazemos, deixa de ser" (p. 123). Diante da inevitabilidade do envelhecimento, Gawande propõe o imperativo da solidariedade e do suporte social para melhorar a experiência individual da velhice e do processo de morrer. Para ele, não é admissível que as pessoas coloquem seus destinos nas mãos de profissionais de capacidade técnica superlativa que, no entanto, não compreendem as necessidades humanas.

Mortais é uma contribuição valiosa para a literatura médica, com desdobramentos para a antropologia da saúde. O livro denuncia deficiências na formação profissional, já sinalizadas por Norbert Elias ${ }^{19}$. Gawande defende a abordagem geriátrica, discute modalidades assistenciais criativas para idosos e estimula a reflexão sobre a indicação de abordagem paliativa para pacientes com doenças incuráveis. Ao contemplar todas essas questões, sustenta-se como obra apurada, de conteúdo atual e urgente, de valor para a sociedade em sentido amplo, e não apenas para profissionais da área da saúde.

\section{Referências}

1. Gawande A. Mortais. Rio de Janeiro: Objetiva; 2015.

2. Becker HS. Boys in white. Chicago: University of Chicago Press; 1961.

3. Good B. Medicine, rationality, and experience: an anthropological perspective. Cambridge: Cambridge University Press; 1994.

4. Ariès P. História da morte no ocidente. Rio de Janeiro: Ediouro; 2003.

5. Lebrão ML. O envelhecimento no Brasil: aspectos da transição demográfica e epidemiológica. Saude Colet. 2007; 4(17):134-40.

6. Cohen L. No aging in India: alzheimer's, the bad family, and other modern things. Berkeley and Los Angeles: University of California Press; 1998.

7. Canguilhem G. O normal e o patológico. 6 a ed. Rio de Janeiro: Forense Universitária; 2009.

8. Roth P. Patrimônio. São Paulo: Companhia das Letras; 2012.

9. Foucault M. História da loucura na idade clássica. São Paulo: Perspectiva; 1978.

10. Sarton M. As we are now. New York: W. W. Norton \& Company Inc; 1973.

11. Foucault M. O nascimento do hospital. In: Foucault M. Microfísica do poder. 3a ed. Rio de Janeiro: Paz e Terra; 2015. p. 171-89.

12. Kane RL, West JC. It shouldn't be this way: the failure of long-term care. Nashville: Vanderbilt University Press; 2005.

13. Goffman E. Manicômios, prisões e conventos. São Paulo: Perspectiva; 1974.

14. Groen H. Tentativas de fazer algo da vida. São Paulo: Planeta; 2016.

15. Menezes RA. A medicalização da esperança: reflexões em torno da vida, saúde/doença e morte. Amazônica: Rev Antropol. 2013; 5:478-98.

16. Sontag S. Doença como metáfora. São Paulo: Companhia das Letras; 2007.

17. WHO. Planning and implementing palliative care services: a guide for programme managers. Geneva: World Health Organization; 2016.

18. Norwood F. The maintenance of life. Durham: Carolina Academic Press; 2009.

19. Elias N. A solidão dos moribundos. Rio de Janeiro: Jorge Zahar; 2001.

Submetido em 09/06/17. Aprovado em 30/06/17. 
